\title{
Importance of HIV cell-to-cell transmission - implications for neutralizing antibody
}

Tuck-Weng Kok* and Peng Li, University of Adelaide, School of Biological Sciences \& School of Medicine, Adelaide, South Australia 5005.

*tuckweng.kok@adelaide.edu.au

\section{Abstract}

Viruses can infect a cell via one or both routes viz. cell-to-cell (c-c) or cell-free (c-f) . Pathogenesis studies of various viruses, including HIV, have shown that c-c transmission yields a significantly higher infection magnitude than the c-f route. Expectedly, potent antibodies inhibited c-f infection more efficiently than with c-cell transmission.

To achieve a one-step, synchronous infection cycle that provides amplified infection, we have studied a consistent and efficient c-c HIV infection model since 1992. H9 cells persistently infected with HTLV-IIIB (H3B cells) and uninfected target CD4+ lymphocyte line (HuT78) were mixed in a ratio of 1:4 respectively. We have recently used this model to produce HIV designer antigens that have been shown to elicit monoclonal as well as polyclonal specific antibodies against novel epitopes that are formed post virus-cell engagement, but prior to fusion. The model can be extended for HIV neutralizing antibody assays or drug inhibitors against high multiplicity of infection.

Keywords: HIV, cell-to-cell transmission, designer antigens, neutralizing antibody, cell-free, high multiplicity of infection.

HIV is one of the most intensely studied human or animal viruses. The holy grail in pursuing the search for an effective vaccine still eludes us. These studies have largely used cell-free virus infection models. Recently more potent and higher amounts of antibodies were reported to be required for viral inhibition during in vitro cell-to-cell HIV transmission compared to cell-free infection (Li et al., 2017). In this cell-to-cell HIV transmission model, the nucleo-fected Jurkat cells were co-cultured with target CCR5-expressing CD4+ T cells. Potent antibodies inhibited cellfree infection very efficiently (up to $95 \%$ ) but failed to completely block cell-to-cell transmission (as low as 36\%) even at saturating concentrations.

In similar cell-to-cell infection studies, HIV-infected human monocyte-derived macrophages cocultured with autologous CD4+ T cells showed that virus transfer was rapid and took place across transient virological synapses (VS) (Jolly et al., 2004; Jolly et al., 2011) as well as demonstrating a high multiplicity of infection (moi) that evaded neutralization to a range of broad spectrum neutralizing monoclonal antibodies (Duncan et al., 2014; Groot, Welsch, and Sattentau, 2008) (see review by (Schiffner, Sattentau, and Duncan, 2013)). Using recombinant gp140 HIV trimers to immunize llamas, R. Weiss and colleagues produced an antibody (J3) (McCoy et al., 2012) that was shown to have particularly potent inhibition of HIV T-cell to T-cell and macrophage-to T-cell spread, but with varying degrees of inhibition (McCoy et al., 2014).

Using the broadly neutralizing antibody (bNAb) PGT121, full protection was shown in macaques when challenged with high-dose intravenous cell-free simian/human immunodeficiency virus $\left(\mathrm{SHIV}_{\mathrm{SF} \text { 162P3 }}\right.$ ) (Parsons et al., 2017). However, and importantly, the same bNAb yielded only partial efficacy after a high dose intravenous cell-associated challenge. HIV, like other retroviruses, infect several orders of magnitude more efficiently via the cell-associated than the cell-free route (Sherer et al., 2007; Smith and Derdeyn, 2017). It is notable that HIV mucosal infection is largely via cellto-cell transmission (Kolodkin-Gal et al., 2013). 
Our laboratory has developed and studied a cell-to-cell HIV infection model since 1992. H9 cells persistently infected with $\mathrm{HTLV}_{\text {-ाшв }}$ [H3B cells] and uninfected target CD4+ lymphocyte line [HuT78] were mixed in a ratio of 1:4 respectively, to achieve a one-step, synchronous infection cycle which provides amplified infection via fusion of viral env and cell membrane (Li and Burrell, 1992). In this model, de novo HIV DNA synthesis was observed within 4 h post infection, concomitant with giant, multi-nucleated fused cells and with linear viral DNA accumulating prior to circular forms. Progeny virus was not released until 24 p.i. as judged by supernatant reverse transcriptase activity. This lag phase is equivalent to the early observations with the one-step growth experiment using phages (Burnet, 1929; Burnet, 1960; d'Herelle, 1926; Ellis and Delbruck, 1939) and suggested a highly efficient initiation of infection with this cell-to-cell transmission route (Li et al., 1992a; Li et al., 1994). This was followed by the release of progeny viral particles within 24-48h (Barbosa et al., 1994; Li and Burrell, 1992; Sato et al., 1992). Other kinetics of cell-to-cell transmission infection with HIV has similarly been reported (Dimitrov et al., 1993).

The mechanisms that cause the requirement for significantly higher concentration of neutralizing antibodies in cell-to-cell transmission vs the cell-free route have not been fully elucidated. There are reports that virological synapse mediates virus transfer during the fusion process (Durham et al., 2012; Jolly et al., 2004). Possible mechanisms for why cell-to -cell HIV infection is less susceptible to neutralizing antibodies are proposed by Smith and Derdeyn (Smith and Derdeyn, 2015; Smith and Derdeyn, 2017)(also see reviews (Jolly and Sattentau, 2013; Sattentau, 2008)). It may be argued that testing viral inhibitors is less likely influenced by cell-to-cell compared with cell-free infection, due possibly to easier access by the smaller molecular weight inhibitors, compared to the larger $150 \mathrm{KDa}$ IgG antibodies (Li et al., 1992a; Vandegraaff et al., 2001) antibodies. The earlier report that AZT did not inhibit HIV cell-to-cell infection (Gupta et al., 1989) contrasts with our findings using the above 1:4 H3B:HuT78 infection model which showed viral inhibition (Li et al., 1992b). However, other groups have reported that the significantly higher yield of virus resulting from cell-to-cell transmission, particularly at lymph nodes, may not all be inhibited by antiretroviral drugs (Duncan, Russell, and Sattentau, 2013; Leong et al., 2016; Sigal et al., 2011) .

Like many scientific advances, the past informs the future. Indeed, it is appropriate here to cite the informative earlier studies of cell-to-cell transmission of infection with other enveloped viruses viz. herpes simplex virus (Black and Melnick, 1955), varicella-zoster virus (Weller, 1953), paramyxoviruses (Merz, Scheid, and Choppin, 1980), lymphocytic choriomeningitis virus (Lehmann-Grube, Slenczka, and Tees, 1969; van der Zeijst et al., 1983) as well as HIV (Gupta et al., 1989). Multi-nucleated, swollen cells were observed despite the absence of infectious material in the fluid phase of the virus-infected cell cultures. Focal lesions were observed to increase in size with time, supporting the idea that viruses can spread from an infected cell to adjacent uninfected cells without the release of free virions in the culture media. Cell-to-cell transmission of paramyxovirus was not inhibited by monospecific antibodies to the HN glycoprotein which mediates viral adsorption. However, it was inhibited by antibodies to the fusion protein which mediates viral penetration (Merz et al., 1980). Cell-to-cell spread can occur either by contact between uninfected and infected cells or from parent to progeny cells during cell division. HIVinfected cells can fuse with uninfected, susceptible cells in which the virus can be transmitted directly in the presence of specific neutralizing antibodies (Gupta et al., 1989). In contrast, the cellto-cell spread of rabies virus infection was inhibited by $>75 \%$ with specific antisera, although nonneutralizing anti-nucleocapsid monoclonal antibodies did not inhibit this viral spread (Lodmell and Ewalt, 1987).

The above cell-to-cell 1:4 transmission infection model yields a moi most likely several orders of magnitude higher and with a much shorter time frame than the cell-free virus route in producing productive infection. In addition to providing a high moi HIV assay to test for bNAbs against cell- 
to-cell transmission, this 1:4 infection model offers a paradigm shift from traditional antigen preparations for potential vaccines or the current mainstream approach of screening elite patients' bNAbs. Using this model we have recently produced temperature-arrested and formaldehyde-fixed prefusion intermediate HIV designer antigens (DAgs) that elicited polyclonal bNAb in guinea pigs and monoclonal antibodies (mAb) from mouse hybridomas (Kok et al., 2014). Preliminary results showed that the antisera exhibited inhibition of both T- and M-tropic HIV, and that the selected mAbs are likely directed against transiently formed and conserved conformational pre-fusion epitopes after viral attachment and receptor engagement, but prior to fully functional viral entry. The DAg specific mAbs do not react with the static/native surface HIV or cellular antigens.

The significantly lower neutralization efficacy with cell-associated virus as against cell-free infection clearly points to the need for consideration of HIV cell-to-cell transmission model in our efforts to raise bNAb against HIV and the need for more suitable in vitro assays in addition to the traditional cell-free infection format. Although the above 1:4 HIV transmission infection mix of $\mathrm{H} 3 \mathrm{~B}$ virus donor and HuT78 recipient cells is an in vitro model, we believe that this may provide a close mimic to pathology (e.g. at lymph nodes) in patients or animal challenge experiments, as currently there is no true laboratory animal model for HIV infection. This model is robust, simple and efficient that can be extended for antibody assays or drug inhibitors against high moi (viz. 1:20 or 1:40 instead of 1:4) cell-associated viral transmission between adjacent cells and production of novel DAgs to elicit bNAbs.

The study approval number is "50109752-285 UoA".

\section{References:}

Barbosa, P., Charneau, P., Dumey, N. and Clavel, F., 1994. Kinetic analysis of HIV-1 early replicative steps in coculture system. AIDS Res and Human Retroviruses 10, 53-59.

Black, F.L. and Melnick, J.L., 1955. Microepidemiology of poliomyelitis and herpes-B infection: spread of the viruses within tissue cultures. J Immunology 74, 236-242.

Burnet, F.M., 1929. A method for the study of bacteriophage multiplication in broth. The Brit J Exptl Path X, 109-115.

Burnet, F.M. 1960. Multiplication and liberation of viruses, Principles of Animal Virology, Academic Press, New York and London, pp. 133-160.

d'Herelle, F., 1926. The bacteriophage and its behaviour. The Williams and Wilkins Co., Baltimore.

Dimitrov, D.S., Willey, R.L., Sato, H., Chang, L.-J., Blumenthal, R. and Martin, M.A., 1993. Quantitation of human immunodeficiency virus type 1 infection kinetics. J Virology 67, 2182-2190.

Duncan, C.J., Russell, R.A. and Sattentau, Q.J., 2013. High multiplicity HIV-1 cell-to-cell transmission from macrophages to CD4+ T cells limits antiretroviral efficacy. AIDS 27, 2201-6.

Duncan, C.J., Williams, J.P., Schiffner, T., Gartner, K., Ochsenbauer, C., Kappes, J., Russell, R.A., Frater, J. and Sattentau, Q.J., 2014. High-multiplicity HIV-1 infection and neutralizing antibody evasion mediated by the macrophage-T cell virological synapse. J Virol 88, 2025 34.

Durham, N.D., Yewdall, A.W., Chen, P., Lee, R., Zony, C., Robinson, J.E. and Chen, B.K., 2012. Neutralization resistance of virological synapse-mediated HIV-1 Infection is regulated by the gp41 cytoplasmic tail. J Virol 86, 7484-95.

Ellis, E.L. and Delbruck, M., 1939. The growth of bacteriophage. J Gen Physiol 3, 365-384. Groot, F., Welsch, S. and Sattentau, Q.J., 2008. Efficient HIV-1 transmission from macrophages to

$\mathrm{T}$ cells across transient virological synapses. Blood 111, 4660-3. 
Gupta, P., Balachandran, R., Ho, M., Enrico, A. and Rinaldo, C., 1989. Cell-to-cell transmission of human immunodeficiency virus type 1 in the presence of azidothymidine and neutralizing antibody. J Virology 63, 2361-2365.

Jolly, C., Kashefi, K., Hollinshead, M. and Sattentau, Q.J., 2004. HIV-1 cell to cell transfer across an Env-induced, actin-dependent synapse. J Exp Med 199, 283-93.

Jolly, C., Welsch, S., Michor, S. and Sattentau, Q.J., 2011. The regulated secretory pathway in CD4(+) T cells contributes to human immunodeficiency virus type-1 cell-to-cell spread at the virological synapse. PLoS Pathog 7, e1002226.

Jolly, C.L. and Sattentau, Q.J., 2013. Attachment factors. Adv Exp Med Biol 790, 1-23.

Kok, T., Gaeguta, A., Finnie, J., Gorry, P.R., Churchill, M. and Li, P., 2014. Designer antigens for elicitation of broadly neutralizing antibodies against HIV. Clin Transl Immunology 3, e24.

Kolodkin-Gal, D., Hulot, S.L., Korioth-Schmitz, B., Gombos, R.B., Zheng, Y., Owuor, J., Lifton, M.A., Ayeni, C., Najarian, R.M., Yeh, W.W., Asmal, M., Zamir, G. and Letvin, N.L., 2013. Efficiency of cell -free and cell-associated virus in mucosal transmission of human immunodeficiency virus type 1 and simian immunodeficiency virus. J Virol 87, 13589-97.

Lehmann-Grube, F., Slenczka, W. and Tees, R., 1969. A persistent and inapparent infection of L cells with the virus of lymphocytic choriomeningitis. J Gen Virol 5, 63-81.

Leong, Y.A., Chen, Y., Ong, H.S., Wu, D., Man, K., Deleage, C., Minnich, M., Meckiff, B.J., Wei, Y., Hou, Z., Zotos, D., Fenix, K.A., Atnerkar, A., Preston, S., Chipman, J.G., Beilman, G.J., Allison, C.C., Sun, L., Wang, P., Xu, J., Toe, J.G., Lu, H.K., Tao, Y., Palendira, U., Dent, A.L., Landay, A.L., Pellegrini, M., Comerford, I., McColl, S.R., Schacker, T.W., Long, H.M., Estes, J.D., Busslinger, M., Belz, G.T., Lewin, S.R., Kallies, A. and Yu, D., 2016. CXCR5(+) follicular cytotoxic T cells control viral infection in B cell follicles. Nat Immunol 17, 1187-96.

Li, H., Zony, C., Chen, P. and Chen, B.K., 2017. Reduced Potency and Incomplete Neutralization of Broadly Neutralizing Antibodies against Cell-to -Cell Transmission of HIV-1 with Transmitted Founder Envs. J Virol 91.

Li, P. and Burrell, C.J., 1992. Synthesis of human immunodeficiency virus DNA in a cell-tocell transmission model. AIDS Res Hum Retroviruses 8, 253-259.

Li, P., Kuiper, L.J., Stephenson, A.J. and Burrell, C.J., 1992a. De novo reverse transcription is a crucial event in cell-to-cell transmission of human immunodeficiency virus. Journal of General Virology 73, 955-959.

Li, P., Kuiper, L.J., Stephenson, A.J. and Burrell, C.J., 1992b. De novo reverse transcription is a crucial event in cell-to-cell transmission of human immunodeficiency virus. J Gen Virol 73 ( Pt 4), 955-9.

Li, P., Stephenson, A.J., Brennan, P.A., Karageorgos, L., Kok, T., Kuiper, L., Swift, J. and Burrell, C.J., 1994. Initiation of reverse transcription during cell-to-cell transmission of human immunodeficiency virus infection uses pre-existing reverse transcriptase. J Gen Virol 75, 1917-1926.

Lodmell, D. and Ewalt, L.C., 1987. Immune sera and antiglycoprotein monoclonal antibodies inhibit in vitro cell-to-cell spread of pathogenic rabies viruses. J Virology 61, 3314-3318.

McCoy, L.E., Groppelli, E., Blanchetot, C., de Haard, H., Verrips, T., Rutten, L., Weiss, R.A. and Jolly, C., 2014. Neutralisation of HIV-1 cell-cell spread by human and llama antibodies. Retrovirology 11, 83.

McCoy, L.E., Quigley, A.F., Strokappe, N.M., Bulmer-Thomas, B., Seaman, M.S., Mortier, D., Rutten, L., Chander, N., Edwards, C.J., Ketteler, R., Davis, D., Verrips, T. and Weiss, R.A., 2012. Potent and broad neutralization of HIV-1 by a llama antibody elicited by immunization. J Exp Med 209, 1091-103.

Merz, D.C., Scheid, A. and Choppin, P.W., 1980. Importance of antibodies to the fusion glycoprotein of paramyxoviruses in the prevention of spread of infection. J Exptl Med $151,275-288$. 
Parsons, M.S., Lloyd, S.B., Lee, W.S., Kristensen, A.B., Amarasena, T., Center, R.J., Keele, B.F., Lifson, J.D., LaBranche, C.C., Montefiori, D., Wines, B.D., Hogarth, P.M., Swiderek, K.M., Venturi, V., Davenport, M.P. and Kent, S.J., 2017. Partial efficacy of a broadly neutralizing antibody against cell-associated SHIV infection. Sci Transl Med 9.

Sato, H., Orenstein, J., Dimitrov, D. and Martin, M., 1992. Cell-to-cell spread of HIV-1 occurs within minutes and may not involve the participation of virus particles. Virology 186, 712-724.

Sattentau, Q., 2008. Avoiding the void: cell-to-cell spread of human viruses. Nat Rev Microbiol $6,815-26$.

Schiffner, T., Sattentau, Q.J. and Duncan, C.J., 2013. Cell-to-cell spread of HIV-1 and evasion of neutralizing antibodies. Vaccine 31, 5789-97.

Sherer, N.M., Lehmann, M.J., Jimenez-Soto, L.F., Horensavitz, C., Pypaert, M. and Mothes, W., 2007. Retroviruses can establish filopodial bridges for efficient cell-to-cell transmission. Nat Cell Biol 9, 310-5.

Sigal, A., Kim, J.T., Balazs, A.B., Dekel, E., Mayo, A., Milo, R. and Baltimore, D., 2011. Cellto-cell spread of HIV permits ongoing replication despite antiretroviral therapy. Nature 477, 95-8.

Smith, S.A. and Derdeyn, C.A., 2015. A pathway to HIV-1 neutralization breadth. Nat Med 21, 1246-7.

Smith, S.A. and Derdeyn, C.A., 2017. New Connections: Cell-to-Cell HIV-1 Transmission, Resistance to Broadly Neutralizing Antibodies, and an Envelope Sorting Motif. J Virol 91.

van der Zeijst, B.A., Noyes, B.E., Mirault, M.E., Parker, B., Osterhaus, A.D., Swyryd, E.A., Bleumink, N., Horzinek, M.C. and Stark, G.R., 1983. Persistent infection of some standard cell lines by lymphocytic choriomeningitis virus: transmission of infection by an intracellular agent. J Virol 48, 249-61.

Vandegraaff, N., Kumar, R., Hocking, H., Burke, T.R., Jr., Mills, J., Rhodes, D., Burrell, C.J. and Li, P., 2001. Specific inhibition of human immunodeficiency virus type 1 (HIV-1) integration in cell culture: putative inhibitors of HIV-1 integrase. Antimicrob Agents Chemother 45, 2510-6.

Weller, T.H., 1953. Serial propagation of in vitro agents producing inclusion bodies derived from varicella and herpes zoster. Proc. Soc. Expt. Biol. Med. 83, 340-346. 